\title{
Research on Motivation Tactics of Middle School Teachers from the Perspective of Occupation Happiness
}

\author{
Min $\mathrm{LI}^{1, \mathrm{a},{ }^{*}}$ \\ ${ }^{1} Y u$ Jingwan area 18-4-601, Shan Haiguan district, Qin Huangdao, China \\ a67663860@qq.com \\ ${ }^{*}$ Corresponding author
}

Keywords: middle school teachers, professional happiness, incentive

\begin{abstract}
Teachers are the honest executors of the school's teaching plan and teaching goal, and they are the most precious for school survival and development of human resources. How to find the right breakthrough point to stimulate, further development and manage, which is the school administrators and education management researchers need to ponder earnestly and face the important issue. Through the empirical study the author found that:(1)The need intensity of middle school teachers from strong to weak order: salary welfare requirements, leadership and management requirements, training, promotion, the work itself, respect, recognition, work environment requirements.(2)The overall demand of middle school teachers is very high, but the satisfaction is low.(3)The needs of different individual characteristics of middle school teachers exist significant differences. Conclusion: this study which is based on empirical investigation of teachers' needs analysis, job satisfaction, motivation preference, build a trinity of middle school teachers incentive strategy, including strengthening the support of society and government ,playing schools leading role, encouraging high school teachers to encourage themselves.
\end{abstract}

\section{Research Background, Purpose and Significance}

\section{Research Background}

Teachers is the most glorious occupation under the sun, in the recent twenty years, their social status, welfare benefits, working conditions, job stress, career goals have changed a lot. Display China human resources development with the media to carry out chinese "job burnout index" survey, the teachers All have occupation burnout ratio as high as 50\%, specially the teachers in primary and middle schools, whose proportion accounted for more than $90 \%$. In fact, in many of our country's secondary school teachers for their own occupation job satisfaction rate is low, the lack of a sense of pride, existence of occupation burnout and abandoned teaching idea. Overall, teachers who cast the human soul, and make people happy as teachers' responsibility (especially middle school teachers), their life is not happy. Lack of teacher's happiness, not only reflects the psychological health problems of this group of teachers, what's more attracted to the national education quality concerns.

The theory of human resource management in the era of knowledge and economy: Those who have the knowledge and skills of knowledge workers, have become the important value of human resources of knowledge capital organization, organization development, promoting economic growth.[1] Teachers are the disseminators of human knowledge and the cultivation of talents, teachers' efficient and creative labor is the important guarantee for high quality education. Therefore, teachers are the most valuable human resources of national survival and development, to improve the quality of education, we must improve the efficiency of teachers and teaching quality. However, in view of the high proportion of school teachers occupation burnout mentioned above, 
how to improve the middle school teachers' work efficiency in this case? How to fully develop this precious human resources? It is not difficult to understand, the most direct way is to enhance teachers' occupation happiness, and eliminate occupation burnout. Human resource is the most important part in secondary school, relativing to teaching facilities, funds, information and technology resources, only to make the teacher resources fully satisfied, can better combine with other elements, to form the best configuration, so as to ensure the secondary education teaching and research activities carried out everything in good order and well arranged, to ensure the quality of secondary education lay a solid foundation for the cultivation of the late talent.

\section{The Research Objective}

\section{Secondary School Teachers Occupation Burnout Index Rose, Unhappy Symptom Highlights}

In recent years, both the public or the media are keen on the teachers' survival state, because the teachers occupation burnout index rose in a straight line. Indeed, a great number of teachers without enthusiasm for work are around us . On their own, they always are tired of work and in anxiety and depression, at the same time emotional sensitivity, suspicion, insomnia, unresponsive, inattention and memory loss present on their bodies ,for students, their patience and love decreased gradually, but the negative emotions communicating with students will imperceptibly infect students, sharpening the interpersonal contradiction, in school, leading to decline in the quality of work occupation , lack of moral, and the loss of a large number of personnel. All of these phenomena which are harm to teachers, students and school development, greatly influenced the teachers' professional development and school development. Therefore, get rid of the teacher occupation burnout, stimulate and maintain teachers working passion has become an important problem not to be ignored.

\section{Secondary School Teacher Incentive Theory Needs Development and Improvement}

Although domestic and foreign incentive theory development has been very mature, all kinds of incentive strategy also show special power, but the incentive strategy for middle school teachers is not enough. The teacher incentive problem from the twentieth Century 80's began to attract the attention of academia, most of these studies based on organizational behavior, management as the theoretical basis, focused on the interpretation of advantages and disadvantages of various incentive method in the reality. Domestic and foreign scholars research on incentive problems of middle school teachers form a consensus, namely the teacher incentive is relatively important for middle school teachers management, the trend of the problem is found in their study, from a focus on higher-level management to focus on teachers' individual subjectivity motivation, from the social standard incentive to incentive teacher standard. But research on teacher motivation mechanism at home and abroad, is mainly based on the advantages and disadvantages of various specific incentive method. which lack of systematic construction of middle school teachers' incentive mechanism, and there is little incentive mechanism based on system of middle school teachers in the perspective of happiness. So this paper hopes that through their own research can make up for this deficiency, can offer some ideas for school administrators and the education department to solve or improve the problems.

\section{The Research Significance}

\section{Theory Significance}

In the study of incentive for teachers in the existing, often from the external factors of the theory itself, or from the perspective of teacher incentive strategy and exploration. While this paper is from the teacher's feelings, to explore the motivation strategies teachers from the perspective of 
happiness, it is also In the study of incentive for teachers in the existing, often from the external factors of the theory itself, or from the perspective of teacher incentive strategy, exploration. While this paper is from the teacher's feelings, to explore the motivation strategies teachers from the perspective of happiness, it is also the innovation spot of this article.

\section{Practical Significance}

is based on the premise of the whole society to concern about teachers occupation burnout ,caused thinking about the lack of middle school teachers happiness, it is the overall summary of current middle school teachers lack of sense of happiness and in-depth analysis of the present situation and causes.

\section{Structure and Lack of Middle School Teacher Occupation Happiness \\ Structure of Middle School Teachers' Occupation Sense of Happiness}

Before the happiness - the ultimate goal of all human pray not satisfied in nature we need, is unable to achieve."[2] and people' requirements are various, but generally can be divided into the need for material and spiritual, and spiritual needs of the people to be extended more than material needs. As a kind of spiritual needs, linked to the high emotional development. The richness of the people's need contact with the diversity of happiness state, at the same time, according to the hierarchy of needs theory of Maslow, need to have a more profound level. In life, the level of demand has always been associated with the development of happiness. Low levels of needs are met, and it will output high level of demands, and the demand will generate higher demand. Demand of people never remain stagnant. Satisfaction of people's need will produce the happy psychological experience, and vice versa. With the replacement of the old and the new demand of happiness, shows a changing trend. For the middle school teachers' occupation, what is occupation happiness? First of all, this kind of happiness comes from the occupation, occupation is the carrier of occupation happiness. From the analysis above, the occupation happiness of middle school teachers comes from the occupation demands of middle school teachers have been met. Therefore, the teacher occupation well being in secondary school consists of middle school teachers' needs and the need to meet .

\section{The Factors Constituting Demands of Middle School Teachers' Occupation Happiness}

the demand of payment and welfare

Happiness is first established in the basic material basis, when economic foundation is stability, people will have a sense of security to survive in society, and let the mood to accept other than material things. As the German playwright Schiller said: "Have the aesthetic as a result of the surplus .in the material" So fair and reasonable salary and welfare will directly affect the well-being of middle school teachers.

the demand of leadership

Leadership is directly represented in leaders' assessment to the work of teachers and the relation between leaders and teachers. Any one of the teachers is very concerned about the assessment of leaders to their work, positive evaluation will enhance self-confidence and sense of happiness of teachers, negative evaluation will hurt self-esteem and sense of happiness of teachers .The relation between leaders and teachers is harmony or not, which will greatly affect the mood when teachers work.

the demand of training and promotion

Training not only can improve the efficiency of the organization, but also greatly promotes the professional development of middle school teachers. So teachers are able to improve their own 
quality ,at the same time the work will be well done, so "Training is the best welfare", which will affect the teachers' occupation happiness, and promotion is the affirmation and encouragement for teachers' work, which will arouse teachers' love for their work, also it will affect teachers' occupation well-being.

the demand of the work itself

Person's life, most of the time is spent in the workplace, the workplace happiness is an important part of happiness. An important prerequisite for the occupation of happiness are matching occupation ideal and reality of occupation well, namely whether the job is their desired occupation. Yes, it will make people feel pleased to put into work, and vice versa. Therefore, whether the teacher occupation is teachers' personal favorite occupation or not affects teachers' occupation well-being.

the demand of respect and recognition

Although the teacher is "spirit of freedom, on behalf of independent personality", but still can not be separated from human society."The most fundamental need is to overcome separation and break the lonely prison."[3] For teachers, his interpersonal relationship derived from the leaders, colleagues, students and parents, the interpersonal relationship is not only to harmony, but also to rise to respect and recognition for his work. The interpersonal relationship between the teachers largely determines whether the pleasure will cause in the work, which affects the teachers' occupation of happiness.

the demand of work environment

Living environment shapes personality, and the work environment can affect the mood of the people. A good working environment, can let a person love to work, make people regard work as a kind of enjoyment, and poor working environment will make people away from work or change jobs. Therefore the work environment affects the teachers' occupation happiness.

The Level of Satisfaction with the Factors Constituting Demands of Middle School Teachers' Occupation Happiness

"To meet the needs" contains two meanings: on the one hand, whether the needs of middle school teachers are met or not, On the other hand, whether this meeting is to achieve its desired level or not. Therefore, if needs don't meet middle school teachers, teachers do not realize happiness, however, if the needs of middle school teachers are met, maybe they aren't happy either, which also contains the expectation of the needs. When the teacher's needs are met and consistent with the teacher's expectations, the teacher will feel happy, when the need for secondary school teachers are met but do not match teacher's expectations, the teacher will not be happy.

\section{Deletion of Middle School Teachers' Occupation Sense of Happiness}

\section{The Performance of Middle School Teachers Without Occupation Happiness}

The most direct manifestations of lack of teachers occupation well being in secondary school is occupation burnout. Occupation burnout, it refers to in the occupation environment, the individual to the long-term emotional stress and interpersonal stress shows a kind of comprehensive symptom containing physiological and psychological dimensions, such as emotional exhaustion, cynical or depersonalization and low personal accomplishment. Masler and Jackson (Maslach \& Jackson, 1996) made the operational definition: emotional exhaustion refers to a person's emotional resources because of the long-term effects of all negative events, leading to burnout and psychological exhaustion, who is unable to make more efforts even can't afford new requirements on the job. Be cynical or depersonalization refers to the individual ignore the communication objects, maintain distance deliberately in itself and the work objects, like criticism and a dig, 
irritable, for themselves and others are negative attitudes. Low achievement refers to the individual gradually hold a negative attitude to measure the relationship between himself and the service objects, are not satisfied with their jobs, depress, want to escape when face the job, have no hope for the future and lack of a sense of achievement.[4] Many survey show that teachers are at high risk of occupation burnout, occupation burnout exists in the teachers. Occupation burnout will inevitably lead to be tired of occupation, unable to experience happiness which occupation bring them. Thus, occupation burnout is a direct manifestation of the lack of occupation happiness related to middle school teachers.

\section{The Root of Middle School Teachers Without Occupation Happiness}

Although the middle school teachers occupation well being is composed of the needs of teachers and the satisfaction of the needs, which does not mean that only meet the needs of teachers or the teacher expectations can enhance the level of teachers' occupation well-being. For example, in recent years, in the optimization of incentive mechanism of teacher, in fact, our country has taken a big step fundamental, pay more attention to the micro main body in incentives, more inclined to multi specification. From merely meet the spiritual needs as the basis, to satisfy the material and spiritual. However, many teachers still there appear the phenomenon of occupation burnout, fail to experience occupation happiness. What is the reason? According to the "complex man" hypothesis, working and living conditions of people in the organization is constantly changing, which will continue to produce new needs and motivation. That is to say, in a given period of life, motivation model is a interaction result of internal needs and external environment. Therefore, the root of the absence of occupation happiness in middle school teachers is not merely to meet the needs.

The cultural roots of the absence of occupation happiness in middle school teachers

Saint oriented culture

Since ancient times, people have to put the cloak on teachers, teachers occupy a high position in the hearts of the people, is a symbol of the human world of the most pure, selfless, noble character. However, teachers are not otherworldly sages, they are human, so they have selfish, profit driven, a variety of personality, but they dared not show it, lest incur social question, fear ruin sage reputation. They are conscientious, try their best to work, become a model for others, and they are strict with themselves. Such a life is wearing a mask of life, is the life with great care, is the life under others evaluation, is a kind of life not real but vain. In such circumstances, who is not tired? Was placed too high expectations, not a kind of pressure? Aloof, and how many people can understand? The sage's expectations make teachers carry a heavy psychological burden, from individual legitimate.

teacher culture

China's education sector suffer the impact of "Kairov" teaching philosophy, and teaching process is regarded as a cognitive process, which is a special kind of cognitive activity, the modern school education system made sufficient affirmation and equipped with the assurance of the system to the cognitive activity, in order to smooth teaching. Curriculum as well as teaching program is chosen and designed well in advance, and the teachers' main task is to make knowledge clear, strengthen the training, in order that students will master the knowledge, and deal with the exam easily, the student's duty is to "accept and grasp", actively cooperate with the teachers to master the knowledge. The classroom life is interpreted as transfer activities of various subjects knowledge, an education among teachers and students is simplified as the goal of education. Teachers were eroded by wisdom and spiritual in teaching activities from day to day, became numb and inflexible teachers.

The social origin of the absence of occupation happiness in middle school teachers

the plight of middle school teachers under social employment pressure 
As society increasingly fierce competition, employment is as the heavy burden in the hearts of the government and people undoubtedly, degree and diploma has become the main basis for the allocation of work and the level of income, and reading is to test and study. In this context, teaching is seen as merely imparting knowledge activities, within a specified time to teach more knowledge, and getting more education benefits has become the best means of educational evaluation. People judge the value of education is more and more utilitarian, concern about utilitarian and usage of education more than education itself. In order to cater to this concern, teachers' life has changed into modern knowledge and skills of production lines, the teacher has become the transfer "mouthpiece" of knowledge and skills , turned into talent engineers, have no Criticism and creativity but work .get away from the study of education, fail to truly experience the happiness that education can bring teachers.

the sigh of middle school teachers under social ethics pressure

Whether from domestic or foreign, social ethics for teachers are very strict. In foreign countries, the National Association of revision in 1975 into a "code of ethics of the education profession", which is mainly for the teachers. Such as wrote in the introduction: "because I believe everyone have their value and dignity, so the first duty of the teacher is to seeking truth, excellence, breeding the democratic. To achieve these goals, the core is to ensure that the freedom to learn and teach, let everyone enjoy the equal right of education. As the teacher's responsibility is to the highest standards to adhere to these ethical principles." From a domestic perspective, the teacher has always been seen as a "model of human morality". Thus, the teacher's ethics requirement is very strict and high standard. The teacher is just a kind of occupation, which is general because its essence is a kind of the occupation for survival and development, which is not common because it is endowed with the highest hope and requirement in many jobs. However, the higher demands, the greater the pressure.

The personal reasons of the absence of occupation happiness in middle school teachers

the particularity of middle school teachers occupation role

The teacher occupation has its particularity, namely play different roles in teaching activities. In the play, the role of the teacher is expanding, and the real self is shrinking. The intrinsic value of teachers' life is shake and fragile, and in the process of playing, teachers are affected by the limited role, on the basis of an enlightened and instill happiness to experience their own happiness. In fact, this happiness is not self desire. The external regulations happiness ignore the internal standard of teachers, and disregard the initiative in the creation and enjoyment, failing to experience and master their own happiness.

the particularity of middle school teachers occupation

Facing a group of teenagers, teaching is originally a very meaningful thing. However, large class size let teachers feel powerless, and even some teachers serve several class, knowledge constantly repeated, the enthusiasm of the teachers has been killing off. Not only that, due to the extension of the work, doing the same work after class, so work pressure is taken from school to home, even the last place to avoid stress is occupied, the huge pressure couldn't be vented as a result. If things go on like this, the teacher will get anxiety, depression and other psychological diseases. In addition, monotonous work environment makes teachers lose the passion. Middle school is the implementation of closed-end management, which made the teacher work into a narrow space every day. They help and guide the students, but their existing problems are unspeakable. The one-way communication exists in this narrow space, and makes the three inch heaven more depressed. 


\section{Establishment of Incentive Strategy for Middle School Teachers From the Perspective of Occupation Well-being}

\section{The Idea and the Body of the Incentive Strategy for Middle School Teachers}

With the rapid development of society, the domestic and international competition is becoming increasingly fierce, the attitude of our government and the national to compulsory education reached a absolute attention. Middle school teachers' social status and the treatment also increased a lot. But the teachers did not experience the hitherto unknown happiness. From the above analysis, it is not difficult to find the reason causing the lack of occupation happiness which contains three aspects, and the single incentive strategy is not enough to meet the needs of teachers, at the same time incentive strategy existing expose problems. This paper put forward the "concept of three-in-one incentive strategy", which shows school should play a leading role, and the government and social should support, meanwhile need teachers' active cooperation.

\section{Specific Implementation of Incentive Strategy in Middle School}

\section{Calls for the Social Rational Treatment for Teachers}

carry forward the culture of tolerance, establish the right expectations for teachers role

Lofty is an evaluation of the outside world, and happiness is the inner experience of an individual, only the inner feelings and experience of people linked activities has a solid foundation and real activity. The teachers have to play the social role defined by the rules from the first day to fulfill the faculty, role specification became teachers yoke. People are accustomed to make the demands on teachers and great expectations for the teachers, but when the teacher cannot accomplish this desire, and all kinds of allegations come thick and fast. But the teacher is also true, both has particularity and the essence of human. People only make an objective evaluation for teachers, regard the teacher as a common person, have reasonable expectations for teachers, and teachers can really relax to improve its quality and dedicate to work, forming happiness.

reconstruct a state of ceremonies, create a good atmosphere of respecting teachers

Our country from the feudal society was honored as " a state of civilization and ceremonies" also "a respect for teachers " country ". However, in modern society, due to the extremely individual teachers problem, a variety of media and people concerned criticize teacher severely, teacher group became the "scapegoat which is not satisfied with the education", leading to the crisis of people on the teacher's respect and trust. To this end, the government has the obligation to use the role of public opinion, guide people to distinguish between truth and falsehood, give teachers more support, help, respect as well as social status, and create a good atmosphere in the society ."Respecting" is not only the basic condition of improving teachers' occupation happiness, but also it is an important symbol of social civilization.

reduce pressure, shape the new mentality of education evaluation

With the development of society and the fierce competition, a hot topic in education become increasingly concerned, which is seem to pay more attention to the talents and children in the state. However, education is an career which makes the human better through the cultivation of people. Professor Zhu Yongxin in the "new education for life a foundation" mentioned: " The most important task of education is to cultivate noble personality, shape the goodness of human nature, and to enable students to have a brilliant life. Judging from the quality of education, that is the origin." I don't think anyone will argue this point of view, but in reality people are most satisfied with the high enrollment rate. In many utilitarian constraints, we changed the original intention of education. This is not the teachers' problem, while it belongs to the whole country and social. 
Therefore, the teachers should be rescued from the high pressure, re-examine the significance of the education to the state and society.

\section{Construct Secure and Effective School Incentive Strategy}

create a comfortable campus environment

If teachers feel like entering a narrow space when entered the campus, it must be caused by environment. Marx once said: "since the human character is caused by the environment, it must make the environment become the rational environment." It is important to create a comfortable campus environment. The campus environment said here, including the hard environment and soft environment. Hard environment refers to the elegant campus material environment and modern equipment, soft environment refers to the harmonious organization atmosphere and the campus culture which can embody the characteristics of school. The school environment is improved, then the teachers are in it, not just work, but a kind of enjoyment, occupation happiness can be greatly improved.

establish scientific training and promotion mechanism

Training is an important part of human resources, through training can make employees constantly charge, which meet the development of their own, but also contribute to the organization of work, therefore the establishment of a scientific and effective training mechanism is very important. Establish training system that can meet the needs of teachers, at the same time ensure the teachers training effect rather than a mere formality.

"Promotion is the most powerful incentive", teachers are the main body and soul of the school, pay attention to the construction of teacher team, focus on the cultivation of excellent teachers who have the ability and a future, based on the correct positioning of school. School should measure teachers form various aspects before promotion, don't suppress the teacher, can't be promoted according to status, and make excellent teachers on a reasonable position to develop their potential.

scientific and democratic leadership and management

School leaders decide the teachers' satisfaction to work mostly. However, because of the defects in the present system of education and the existence of official standard thought, the teachers as well as are placed on the regulated status. As a result of frequent standard assessment, performance appraisal, and heavy examination requirements, teachers almost lost educational sovereignty. Therefore, to improve school management mode, the majority of teachers should be actively participate in democratic management, which is an important means to improve the job satisfaction.

\section{Play the Main Spirit of Teachers}

accept teacher occupation, culture Occupation of pride

"Happy degree mostly is decided of one' own ", if the teacher feel occupation burnout, but don't have enough courage to say goodbye to the education, so only embrace in her occupation in good faith, concentrate on their occupation, who can be self-rescued in the endless sea. Changing a kind of angle to think will have the courage and the power to face it. Learn to regulate their emotions and take it lightly in the face of loneliness, feel pleased to have a stable occupation, and find their own advantage in the occupation facing a group of youthful and pure child, feel proud to have such a sacred occupation at last.

improve the professional level, take the road of happy research,

The classroom is the stage of the middle school teachers, good or bad performance depends entirely on the performer's foundation. For teachers, the higher professional level is, the better they perform, that contribute to attract the students attention, which also makes teachers experience more fun that the classroom bring them. Thus, promoting the teachers' professional development is an 
important way to promote the teacher occupation well-being, and it does not exist if it left the teaching process .Happiness is not a passive waiting, but comes from the creative work.

\section{Reference}

[1]Jiang Xu. Study on the incentive mechanism of needs analysis based on the middle school teachers.[D] Master Thesis of East China Normal University, 2009:1.

[2].Gray.Human happiness [M]., The Commercial Press,1963:11

[3] Frome. The art of love [M]. Chengdu: Sichuan people's publishing house, 1986:10.

[4]Wu Zengqiang, Sheng Zhifei. The psychological growth of teacher career[M]. Shanghai: Shanghai Technology Education Press, 2008(6):148

[5]Tan Chuanbao. Teachers' Ethics[M]. Beijing: Beijing Normal University press, 2003:48. 